\title{
Short-Term Effects of Nose-Only Cigarette Smoke Exposure on Glutathione Redox Homeostasis, Cytochrome P450 1A1/2 and Respiratory Enzyme Activities in Mice Tissues
}

\author{
Haider Raza ${ }^{a}$ Annie John ${ }^{\mathrm{a}}$ Abderrahim Nemmar ${ }^{\mathrm{b}}$ \\ aDepartment of Biochemistry and bepartment of Physiology, College of Medicine and Health Sciences, \\ UAE University, Al Ain, United Arab Emirates
}

\section{Key Words}

Cigarette smoke • Oxidative stress $•$ Cytochrome P450 • Glutathione • Mitochondria

\begin{abstract}
Background/Aims: The components of cigarette smoke (CS) have been implicated in the development of cancer as well as in cardiopulmonary diseases. We have previously reported increased oxidative stress in rat tissues induced by tobacco-specific toxins nicotine and 4-(N-methyl-N-nitrosamino)-1-(3-pyridyl)-1-butanone (NNK). Recently, we have also shown increased oxidative stress and associated inflammatory responses in various tissues after exposure to cigarette smoke. Methods: In this study, we have further investigated the effects of nose-only cigarette smoke exposure on mitochondrial functions and glutathionedependent redox metabolism in tissues of BALB/C mice. Liver, kidney, heart and lung tissues were analyzed for oxidative stress, glutathione (GSH) and cytochrome P450 dependent enzyme activities and mitochondrial functions after exposure to smoke generated by 9 cigarettes/day for 4 days. Control mice were exposed to air only. Results: An increase in oxidative stress as observed by increased production of reactive oxygen species (ROS) and altered GSH metabolism was apparent in all the tissues, but lung and heart appeared to be the main targets. Increased expression and activity of CYP450 1A1 and 1A2 were also observed in the tissues after exposure to cigarette smoke. Mitochondrial respiratory dysfunction in the tissues, as observed by alterations in the activities of Complex I and IV enzymes, was also observed after exposure to cigarette smoke. SDS-PAGE and Western blot results also indicate that alterations in the expression of enzyme proteins were in accordance with the changes in their catalytic functions. Conclusion: These results suggest that even short term exposure of cigarette smoke have adverse effects on mitochondrial functions and redox homeostasis in tissues which may progress to further complications associated with chronic smoking.
\end{abstract}




\section{Introduction}

Cigarette smoking and tobacco smoke-related diseases, such as pulmonary disorders, cardio and cerebrovascular diseases and cancers, cause millions of death per year and is also responsible for more than $35 \%$ all cancer deaths $[1,2]$. There are a number of tobaccorelated active compounds, such as nicotine, NNK, other nitrosamines and aromatic amines and polycyclic aromatic hydrocarbons which are known toxicants and carcinogens [3-5]. Cigarette smoke (CS) and its main component nicotine and NNK have also been shown to induce cytochrome P450 activities in the liver and other tissues [6, 7]. Alterations in CYP activities and expression are related to the increased oxidative stress and risk for cancer development [7, 8]. Moreover, exposure to cigarette smoke have also been reported to cause a decrease in antioxidant glutathione (GSH) concentration and antioxidant enzymes such as GSH-Px, superoxide dismutase (SOD) and catalase [9]. Studies, including our own, have previously shown that nose-only CS exposure cause increase in oxidative stress, inflammatory responses and endothelial dysfunction in mice and human tissues [1, 2, 10-13]. The lung and heart tissues appear to be the specific targets for the cigarette smoke-induced toxicity. Moreover, smoking is also implicated in many other chronic conditions such as dyslipidemia, glucose intolerance and abnormal nutritional bioenergetics metabolism [14]. Despite the significance of tobacco smoke induced diseases, the link between tissue specific responses and disease etiology remains unclear. We therefore investigated the effects of short term nose-only CS on GSH-dependent redox homeostasis, oxidative stress, cytochrome P4501A1/1A2 expression and activities of mitochondrial respiratory enzyme complexes in BALB/C mice liver and other tissues. Our results suggest that even short term exposure to CS caused an increase in oxidative stress and alterations in CYP activities and mitochondrial functions in other tissues as well, in addition to the lung and heart as target tissues. Thus CS exposure, even for a short time, may have consequences associated with drug metabolism/ detoxification, oxidative stress and mitochondrial dysfunction in tissues. Although in this study, a mouse model has been used to investigate the effects of direct exposure of nose-only CS, our results may be significant in understanding the adverse effects of CS in humans as well.

\section{Materials and Methods}

Cytochrome c, cumene hydroperoxide, NADH, NADPH, dithionitrobenzoic acid,resorufin, 7-ethoxyresorufin, methoxyresorufin, glutathione (GSH), oxidized glutathione (GSSG), glutathione reductase, malonedialdehyde, thiobarbituric acid and, ubiquinone were purchased from Sigma-Aldrich Fine Chemicals (St Louis, MO, USA). 2', 7'- Dichlorofluorescein diacetate (DCFDA) was procured from Molecular Probes (Eugene, OR, USA). Polyclonal antibodies against CYP1A1 and CYP 1A2 were purchased from Amersham Int. Plc. (Amersham, UK), $\beta$-actin from Santa Cruz Biotech. Inc. (Santa Cruz, CA,USA) and GSH-Px from Abcam Ltd., Cambridge, UK. Reagents for SDS-PAGE and Western blot analyses were purchased from BioRad Laboratories (Richmond, CA, USA).

\section{Animals and treatment with CS}

BALB/ c mice (Taconic Farms Inc. Germantown, NY,USA) were maintained in the College of Medicine and Health Sciences animal house on a 12-hour light-dark cycle. The animals $(n=8)$ were placed in cages and supplied with pelleted food and water ad libitum. All the experiments were performed in accordance with the protocols approved by the Institutional Animal Care and Research Advisory Committee. Following 1 week of acclimatization, animals were randomly divided into two groups: control $(n=8)$ and CS-exposed group $(n=8)$. The mice were placed in soft restraints and connected to the exposed tower. Animals were exposed to mainstream CS generated by commercially available filtered cigarettes (Marlboro, $12 \mathrm{mg}$ tar/1.0 mg nicotine; Philip Morris, Richmond, VA,USA) through their noses using a nose-only exposure system (InExpose System,Scireq, Canada). A computer-controlled puff was generated every minute, leading to 10 seconds of CS exposure followed by 50 seconds of fresh air. CS-exposed group inhaled smoke from 9 
consecutive cigarettes per day for 4 days as described before [15]. The CS doses and time of exposure chosen in the present study was associated with a good tolerance of mice to the CS sessions without mortality, and an acceptable level of particulate density concentration according to the published reports and as described before[12,13]. Control mice were treated similarly and were exposed to filtered air for the same duration. The total particulate density concentration of CS was measured daily and indicated an average of $420.5 \mathrm{mg}$ total particulate matter per $\mathrm{m}^{3}\left(\mathrm{TPM} / \mathrm{m}^{3}\right)$ in the smoke tower.

\section{Tissue homogenization and fractionation}

After the given time of exposure, liver, kidney, heart and lung tissues from air-exposed control and CS exposed BALBc mice were collected and rinsed with ice-cold PBS ( $\mathrm{pH}$ 7.4) before homogenization in $0.1 \mathrm{M}$ phosphate buffer $\mathrm{pH} 7.4$ containing $0.15 \mathrm{M} \mathrm{KCl}, 0.1 \mathrm{mM}$ EDTA, $1 \mathrm{mM}$ DTT and $0.1 \mathrm{mM}$ phenylmethylsulfonylfluoride at $4^{\circ} \mathrm{C}$. Homogenate was centrifuged for 10 minutes at $3000 \mathrm{xg}$ to remove cellular debris and supernatants were used for further analysis. Protein content was measured by Bradford's method as described before $[12,16]$.

Measurement of ROS and lipid peroxidation

ROS in different tissues of control and CS-treated mice was measured using DCFDA as a fluorescent probe as described before $[7,12,13,17]$.

NADPH-dependent membrane lipid peroxidation was measured as thiobarbituric acid reactive substance using malonedialdehyde as standard [18].

Measurement of GSH concentration and metabolism

GSH concentration and enzymes of GSH metabolism, glutathione peroxidase (GSH- Px), were measured in the tissues from control and CS exposed animals by standard procedures as described in previous publications $[12,13,19,20]$.

Measurement of CYP activities

CYP1A1 and CYP1A2 activities in the tissues from control and treated mice were measured using standard substrates, 7-ethoxyresorufin and methoxyresorufin, respectively as described previously [21, 22].

Measurement of mitochondrial respiratory enzyme activities

Mitochondrial respiratory Complex I and Complex IV enzyme activities were measured with ubiquinone and cytochrome $\mathrm{c}$ as substrates respectively according to the methods of Birch-Machin et al. [23] as described recently [18, 20].

\section{SDS-PAGE and Western blot analysis}

Protein $(50 \mu \mathrm{g})$ from control and smoke exposed mice tissue homogenates were separated on $12 \%$ SDS-PAGE and electrophoretically transferred onto nitrocellulose paper by Western blotting using the standard procedures of Laemmli [24] and Towbin et al. [25] as described before. The immunoreacting protein bands were visualized after interacting with primary antibodies against GSH-Px, CYP1A1 and CYP1A2. Actin expression in each tissue was used as loading control.

\section{Statistical analysis}

Values were calculated as mean \pm S.E.M. of at least three determinations. Statistical significance of the data was assessed using Student's' $t$ ' test and $p$ values $<0.05$ were considered significant.

\section{Results}

Effect on ROS production

Nose-only CS exposure significantly increased the production of ROS in the kidneys, heart and lungs of the BALB/c mice (Fig. 1). Liver, on the other hand exhibited no appreciable increase in ROS production. This may be due to increased scavenging of ROS in the liver by higher GSH pool. 


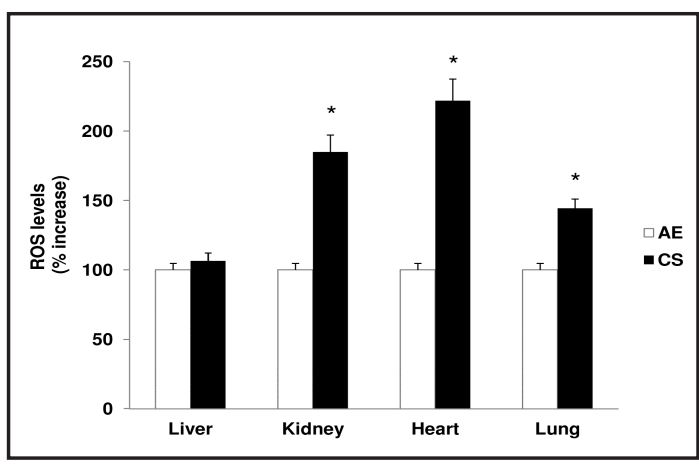

Fig. 1. Effect of CS on ROS production. ROS in the tissues from control and CS exposed mice were measured using DCFDA as a probe as described in Materials and Methods. ROS-induced fluorescence was measured using the Schimadzu spectrofluorophotometer with excitation $488 \mathrm{~nm}$ and emission $525 \mathrm{~nm}$. Results are expressed as mean \pm S.E.M. from three independent experiments and asterisks indicate significant difference $\left({ }^{*} \mathrm{p}<0.05\right)$.

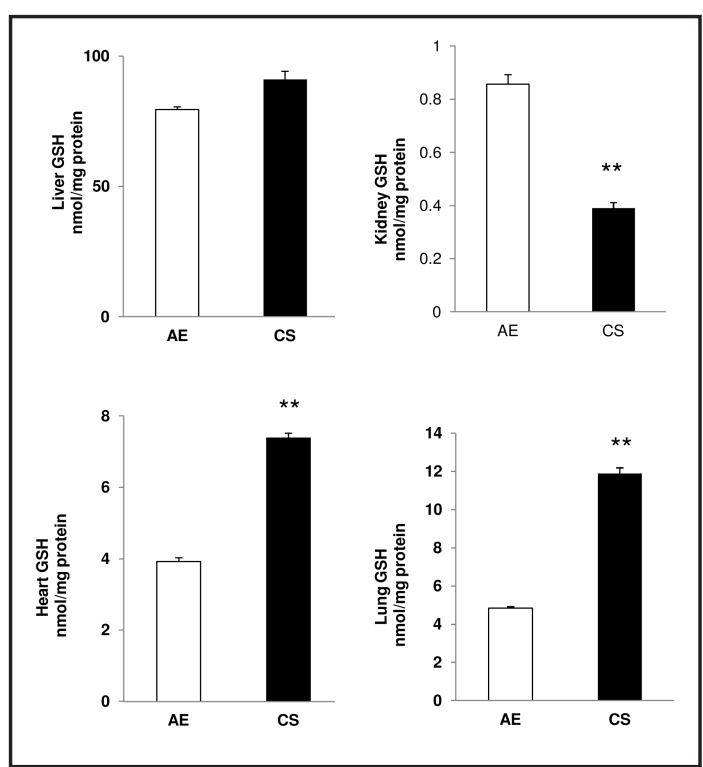

Fig. 2. Effect of CS on GSH concentration. GSH concentrations in the tissues of control and CS exposed mice was measured by the recycling method of Griffith using NADPH for enzymatic conversion of oxidized glutathione to GSH which was then measured by conjugating with DTNB as described before [12, 13]. Results are expressed as mean \pm S.E.M. from three independent experiments and asterisks indicate significant difference $\left({ }^{*} \mathrm{p}<0.05\right.$ and $\left.{ }^{* *} \mathrm{p}<0.01\right)$.

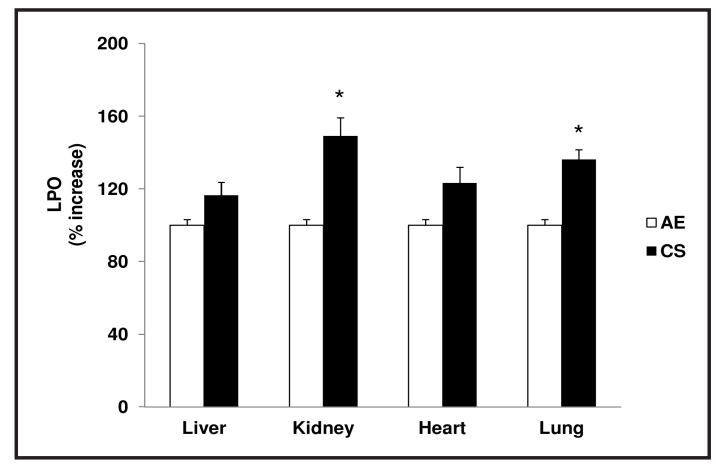

Fig. 3. Effect of CS on LPO. NADPH-supported membrane lipid peroxidation was measured as TBARS using malonedialdehyde as a standard as described in the Materials and Methods. Results are expressed as mean \pm S.E.M. from three independent experiments and asterisks indicate significant difference $(* \mathrm{p}<0.05)$.

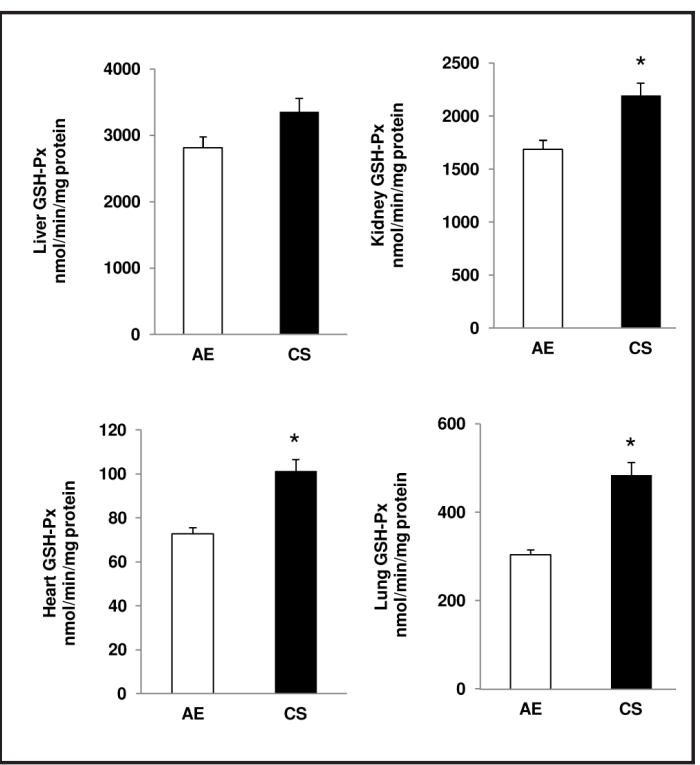

Fig. 4. Effect of CS on GSH-Px activity. GSH-Px activity, using cumene hydroperoxide as a substrate was measured in the tissues from control and CS exposed mice as described in the Materials and Methods. Results are expressed as mean \pm S.E.M. from three independent experiments and asterisks indicate significant difference $\left({ }^{*} \mathrm{p}<0.05\right)$.

\section{Effect on GSH content}

CS exposure exhibited differential effects on GSH pool in the kidney, liver, lung and heart (Fig. 2). While the GSH content was markedly low in CS exposed mice kidney it was 
Fig. 5. Effect of $\mathrm{CS}$ on CYP1A1 activity. CYP $1 \mathrm{~A} 1$ activity, using ethoxyresorufin as a substrate was measured in the tissues from control and CS exposed mice as described in the Materials and Methods. Results are expressed as mean \pm S.E.M. from three independent experiments and asterisks indicate significant difference $(* \mathrm{p}<0.05)$.

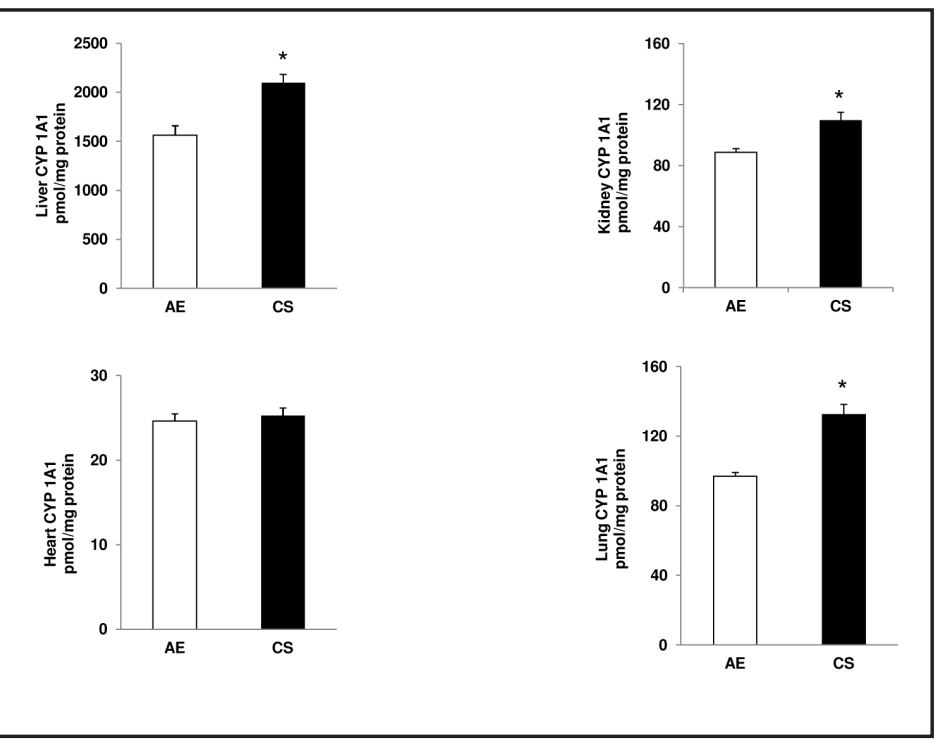

Fig. 6. Effect of CS on CYP $1 \mathrm{~A} 2$ activity. CYP $1 \mathrm{~A} 2$ activity, using methoxyresorufin as a substrate was measured in the tissues from control and CS exposed mice as described in the Materials and Methods. Results are expressed as mean \pm S.E.M. from three independent experiments and asterisks indicate significant difference $\left({ }^{*} \mathrm{p}<0.05\right)$.

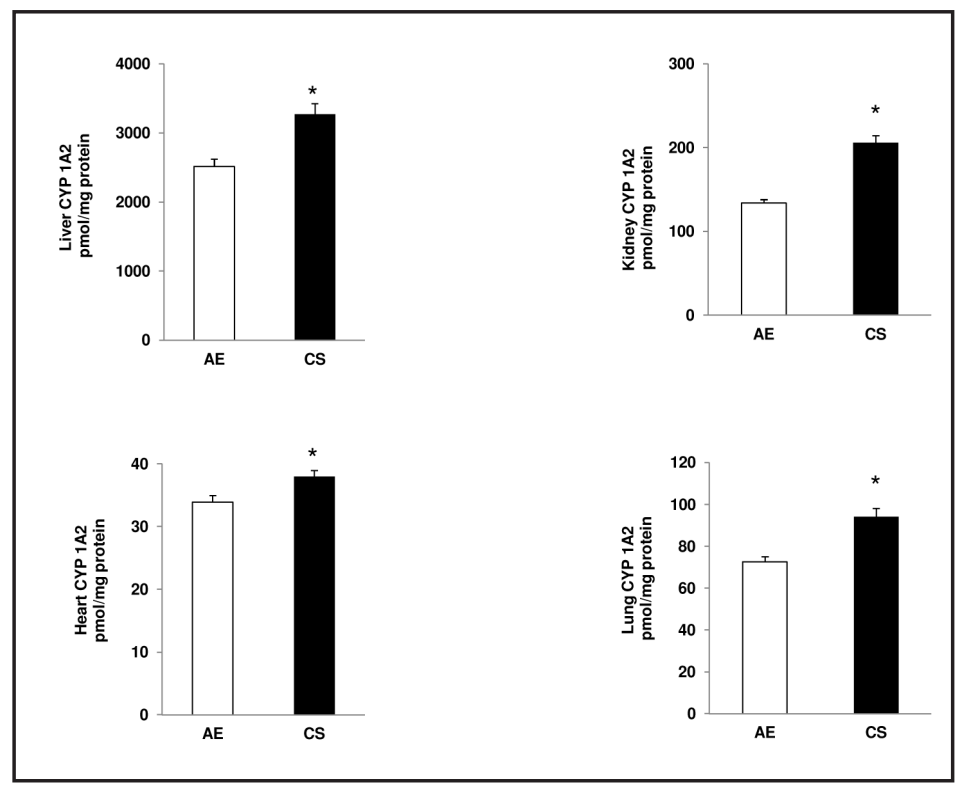

significantly higher in the heart and lungs of the CS exposed mice in comparison with air exposed mice. The liver, on the other hand has the greatest pool of GSH which is not significantly affected after CS exposure.

\section{Effect on $L P O$}

CS exposure increased LPO in all the tissues studied. However, the lungs and kidney exhibited significantly higher rate of LPO after CS exposure in comparison with the liver and heart (Fig. 3).

\section{Effect on GSH-Px}

CS increased the activity of antioxidant enzyme, GSH-Px moderately (14\%)in the liver. GSH-Px activity was significantly increased in the kidney, heart and the lungs (35-70\%) suggesting the activation of defense mechanisms against increased ROS production and oxidative stress (Fig. 4). 
Fig. 7. Effect of CS on mito-

Raza/John/Nemmar: Tissue-Specific Cigarette Smoke Toxicity chondrial Complex I activity. Mitochondrial respiratory enzyme, Complex I was measured using ubiquinone as substrate as described in the Materials and Methods. Results are expressed as mean \pm S.E.M. from three independent experiments and asterisks indicate significant difference $\left({ }^{*} \mathrm{p}<0.05\right.$ and ${ }^{* *} \mathrm{p}<0.01$ ).
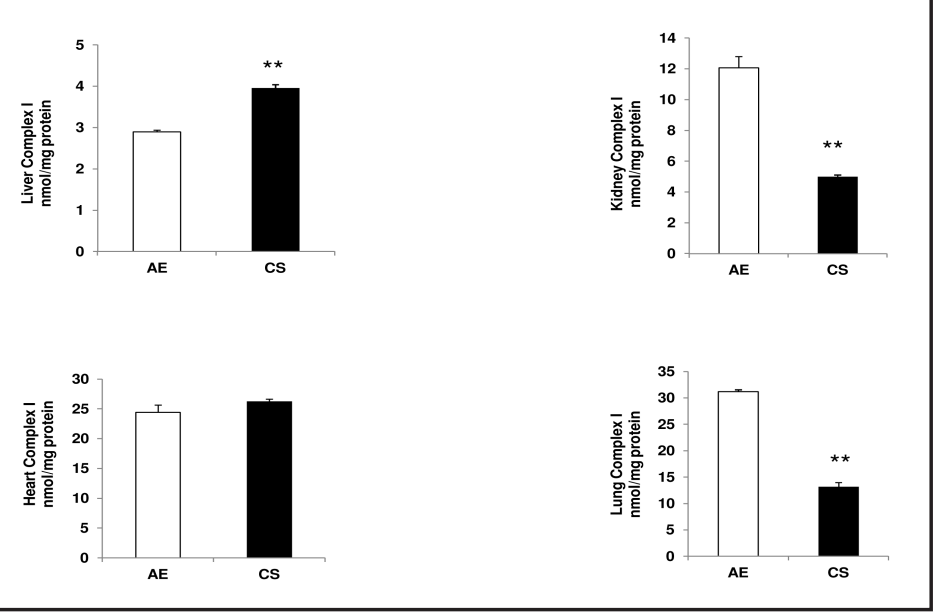

Fig. 8. Effect of CS on mitochondrial Complex IV activity. Mitochondrial respiratory enzyme, Complex IV was measured using cytochrome $\mathrm{c}$ as substrate as described in the Materials and Methods. Results are expressed as mean \pm S.E.M. from three independent experiments and asterisks indicate significant difference $\left({ }^{*} \mathrm{p}<0.05\right.$ and ${ }^{* *} \mathrm{p}<0.01$ ).

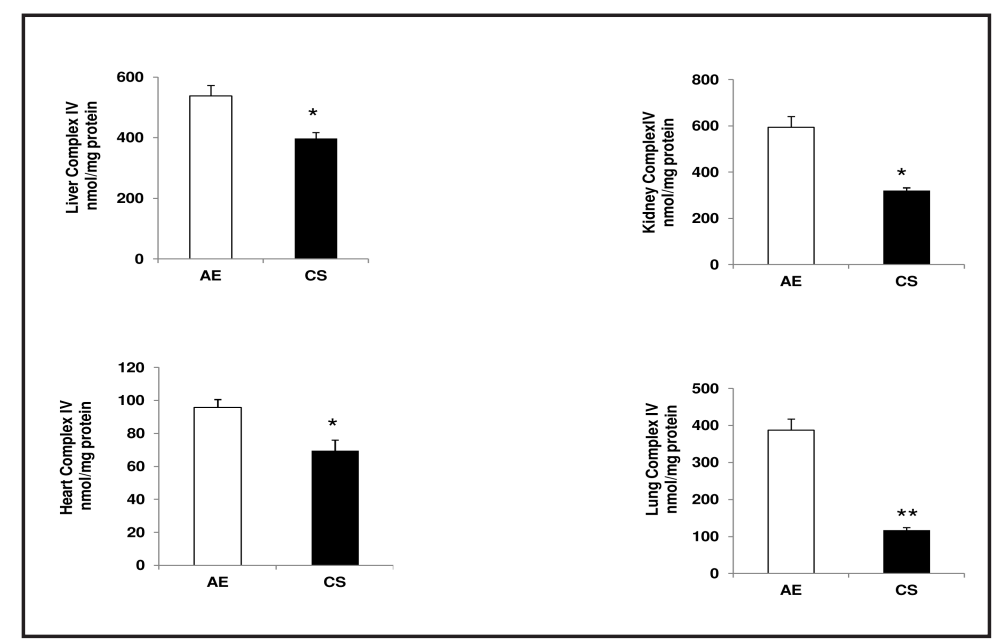

Effect of CS on the tissue-specific CYP1A1/1A2 enzyme activities

With the exception of heart, CS exposure significantly increased (30-45\%) the activity of ethoxyresorufin deethylase which is mainly catalyzed by the CYP $1 \mathrm{~A} 1$ isoform (Fig. 5). CYP $1 \mathrm{~A} 1$ activity was not altered significantly in the heart tissue of BALB/c mice after CS exposure.

Similarly, the activity of CYP $1 \mathrm{~A} 2$ as measured by its preferred substrate, methoxyresorufin, was also significantly increased in the mice tissues after CS exposure (Fig. 6). These results suggest a differential response of metabolic activation against CS constituents in different tissues. This may also suggest a differential susceptibility in the tissues of mice towards the toxicity of nose-only CS exposure.

Effects of cigarette smoke on tissue-specific mitochondrial respiratory enzyme complex activities

A differential effect of CS exposure on mitochondrial complex I (NADH-ubiquinone oxidoreductase) activity was observed in BALB/c mice tissues. Complex I activity was found to be significantly increased (37\%) in the liver of CS exposed mice while the kidneys and lungs exhibited a marked decrease in the enzyme activity (Fig. 7). The heart exhibited no significant change when compared with air exposed mice.

Mitochondrial respiratory Complex IV (cytochrome c oxidase) activity on the other hand was significantly inhibited in the liver, kidney, heart and lung tissues in CS exposed mice (Fig. 8). This may be due to the increased sensitivity of Complex IV enzyme towards ROS and oxidative stress. 
Fig. 9. Effect of $\mathrm{CS}$ on the expression of enzyme proteins. Protein $(50 \mu \mathrm{g})$ from liver, kidney, heart and lung of CS and airexposed (AE) mice were subjected to $12 \%$ SDS-PAGE [24] and Western blot analyses [25] to visualize immunoreactivity of GSH-Px, CYP $1 \mathrm{~A} 1$ and CYP 1A2 proteins. Beta-actin was used as a loading control. R.I values indicate relative intensity (of the protein band) using expression of the proteins in $\mathrm{AE}$ tissues as 1.0. The figures are representative of 2-3 experiments. Molecular weights shown are in $\mathrm{kDa}$.

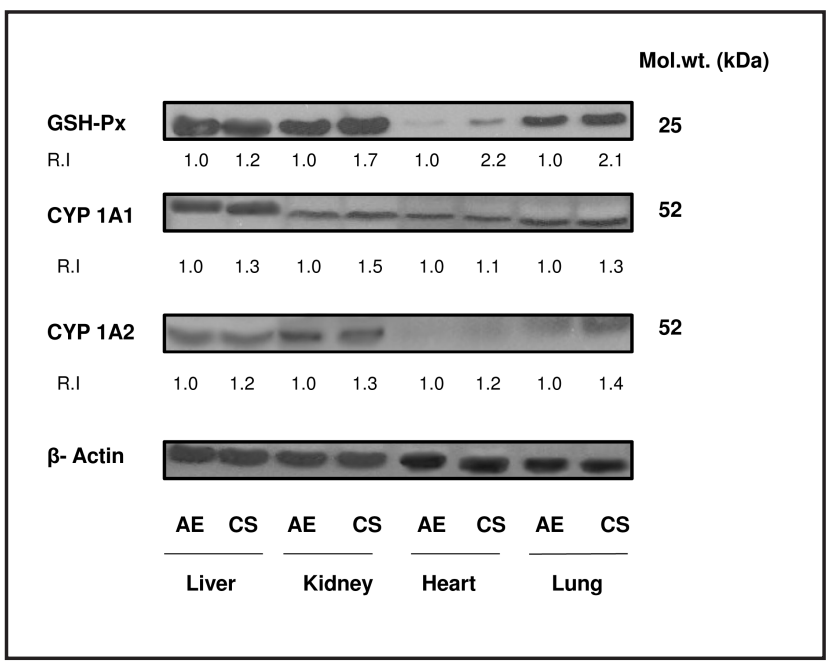

Effect of cigarette smoke on the tissue-specific expression of enzyme proteins

As shown in Figure 9, the expression of GSH-Px protein was significantly increased (1.22.2 fold) in the order, heart>lung > kidney> liver after CS exposure when compared to air exposed animals (Fig. 9). The expression of CYP1A1 and CYP1A2 enzyme proteins was also increased in the tissues of animals exposed to CS confirming the increased catalytic activities of these enzymes after CS exposure.

\section{Discussion}

Cigarette smoking can increase systemic oxidative stress [26], alter nitric oxide (NO) and reactive oxygen species bioavailability and cause endothelial and cardiac dysfunction $[12,13,27]$. Cigarette smoke is a complex mixture of thousands of constituents and induces the production of reactive oxygen species (ROS). Particulate tar and gas phase smoke component of CS also contain many semiquinone radicals, ROS and reactive nitrogen species (RNS) and carbon monoxide which have been associated with various chronic pulmonary and cardiovascular diseases ranging from inflammation to cancer [28]. GSH plays a major role in protecting biomolecules from oxidative damage caused by cigarette smoke. Our results have shown a significant increase in ROS production in the lung, heart and kidneys by CS. However, GSH concentration appears to be increased significantly in the lung and heart, suggesting activation of the defensive response in these tissues. On the other hand, the GSH level in the kidneys remained significantly lower than control suggesting increased oxidative stress in this tissue. This may be associated with increased detoxification, conjugation and excretion of CS toxicants with GSH in the kidney. Increase in LPO in short term CS exposed tissues could also be attributed to the increase in ROS and altered GSH metabolism. This was also supported by the observation that the activity of the antioxidant enzyme, GSH-Px, was increased in all the tissues. The transient and repeated oxidative stress burstin different tissues have been reported after cigarette smoke within 3 hours of exposure and this may have consequences in increasing the oxidative stress and maintaining the GSH-dependent antioxidant homeostasis $[10,29,30]$.

Our results have shown increased activities and expression of both CYP1A1 and CYP1A2 in the tissues of CS exposed mice. Previous studies have reported that short term exposure to CS induced both CYP 1A1 and CYP1A2 expression, preferably inducing CYP1A1 in long term CS exposure [31]. Our previous results have also shown the differential induction of phase 1 and phase 2 enzymes in tissues treated with CS major components using nicotine and NNK $[17,21]$. This induction of CYP 1A1/1A2 enzymes after CS exposure may have implications in the metabolic activation and detoxification of carcinogens present in CS. These results 
suggest that smokers may have altered efficiency in metabolic activation and detoxification of toxic chemicals compared to non-smokers.

CS also caused mitochondrial dysfunction in the tissuse of mice exposed to CS as observed by the inhibition of Complex I and Complex IV enzyme activities. A decrease in ComplexIV activity has been reported in chronic human smokers [32]. Increased oxidative stress caused by CS, especially in the lung, also induces changes in mitochondrial functions, inducing apoptosis and alterations in bioenergetics [33]. Both nicotine and carbon monoxide have been implicated in altering mitochondrial dysfunction and metabolic injury. A significant decrease in the rate of respiration as well as oxidative phosphorylation in the mitochondria was found after CS exposure [7, 20, 34]. Acrolein, a highly toxic CS pyrolysis aldehyde product and 4-HNE, a highly reactive product of LPO are also known to induce mitochondrial dysfunction [35, 36]. Mitochondrial dysfunctions associated with reduced bioenergeticsand oxidative stress induced by CS are associated with increased apoptotic and necrotic cell death $[37,38]$.

\title{
Conclusion
}

Our study has shown that even a short term exposure (4 days only) to CS increased oxidative stress in mice tissues, which is associated with mitochondrial dysfunction and altered ability for metabolic activation and detoxification of CS toxicants.

\begin{abstract}
Abbreviations
CS (Cigarette smoke); CYP450 (cytochrome P450);DCFDA (dichlorofluorescein diacetate); NNK (4-(N-methyl-N-nitrosamino)-1-(3-pyridyl)-1-butanone); GSH (glutathione); GSH-Px (glutathione peroxidase); LPO (lipid peroxidation); ROS (reactive oxygen species); SDS-PAGE (sodium dodecylsulphate polyacrylamide gel electrophoresis).
\end{abstract}

\section{Conflict of interest}

No conflict of interest to disclose for any of the authors

\section{Acknowledgements}

This study was supported by Terry Fox Cancer Research Funds and by the Research Committee Grants from College of Medicine and Health Sciences, UAE University, Al Ain, UAE.

\section{References}

1 Lee J, Cooke JP: Nicotine and pathological angiogenesis. Life Sci 2012;91:1065-1069.

-2 Russo P, Cardinale A, Margaritara S, Cesaria A: Nicotine receptor and tobacco-related cancer. Life Sci 2012;91:1087-1092.

3 Hoffmann D, Rivenson A, Chung FL, Wynder EL: Potential inhibitors of tobacco carcinogenesis. Ann N Y Acad Sci 1993;686:140-160.

4 Chen SY, Wang LY, Lunn RM, Tsai WY, Lee PH, Lee CS, Ahsan H, Zhang YJ, Chen CJ, Santella RM: Polycyclic aromatic hydrocarbon-DNA adducts in liver tissues of hepatocellular carcinoma patients and controls. Int J Cancer 2002;99:14-21.

5 Purohit V, Rapaka R, Kwon OS, Song BJ: Roles of alcohol and tobacco exposure in the development of hepatocellular carcinoma. Life Sci 2013;92:3-9. 


\section{Cellular Physiology $\quad$ Cell Physiol Biochem 2013;31:683-692 and Biochemistry

6 Joshi M, Tyndale RF: Regional and cellular distribution of CYP2E1 in monkey brain and its induction by chronic nicotine. Neuropharmacology 2006;50:568-575.

7 Bhagwat S V, Vijayasarathi C, Raza H, Mullick J, Avadhani NG: Preferential effects of nicotine and NNK on mitochondrial GSTA4-4 induction and increased oxidative stress in the rat brain. Biochem Pharmacol 1998;56:831-839.

-8 Rahman MM, Elmi S, Chang TKH, Bai N, Sallam NA, Lemos BS, Moren-Afshari F, Laher I: Increased vascular contractility in isolated vessels from cigarette smoke rats is mediated by basel endothelin release. Vasc Pharmacol 2007;46:35-42.

9 Avti PK, Kumar S, Pathak CM, Vaiphei K, Khanduja KL: Smokeless tobacco impairs the antioxidant defense in liver, lung, and kidney of rats. Toxicol Sci 2006;89:547-553.

10 Valenca SS, Silva BF, Lopes AA, Romana-Souza B, Marinho Cavalcante MC, Lima AB, Goncalves KV, Porto LC: Oxidative stress in mouse plasma and lungs induced by cigarette smoke and lipopolysaccharide. Environ Res 2008;108:199-204.

11 Barbieri SS, Zacchi E, Amadio P, Gianelli S, Mussoni L, Weksler BB, Tremoli E: Cytokines present in smokers' serum interact with smoke components to enhance endothelial dysfunction. Cardiovasc Res 2011;90:475483.

12 Nemmar A, Raza H, Subramaniyan D, John A, Elwasila M, Ali BH, Adeghate E: Evaluation of the pulmonary effects of short-term nose-only cigarette smoke exposure in mice. Exp Biol Med 2012;237:1449-1456.

13 Nemmar A, Raza H, Subramaniyan D, Yasin J, John A, Ali BH, Kazzam EE: Short-term systemic effects of noseonly cigarette smoke exposure in mice: role of oxidative stress. Cell Physiol Biochem 2013;31:15-24.

14 Jensen EX, Fusch C, Jaeger P, Peheim E, Horber FF: Impact of chronic cigarette smoking on body composition and fuel metabolism. J Clin Endocrinol Metab 1995;80:2181-2185.

15 Vlahos R, Bozinovski S, Chan SP, Ivanov S, Lindén A, Hamilton JA, Anderson GP: Neutralizing granulocyte/ macrophage colony-stimulating factor inhibits cigarette smoke-induced lung inflammation. Am J Respir Crit Care Med 2010;182:34-40.

16 Raza H, Ahmed I, John A, Sharma AK: Modulation of xenobiotic metabolism and oxidative stress in chronic streptozotocin induced diabetic rats fed with Momordica charantia fruit extract. J Biochem Mol Toxicol 2000;14:131-139.

17 Raza H, John A: Streptozotocin-induced cytotoxicity, oxidative stress and mitochondrial dysfunction in human hepatoma HepG2 cells. Int J Mol Sci 2012;13:5751-5767.

-18 Raza H, Prabu SK, Robin MA, Avadhani NG: Elevated mitochondrial cytochrome P4502E1 and glutathione S-transferase A4-4 in streptozotocin-induced diabetic rats. Tissue specific variations and roles in oxidative stress. Diabetes 2004;53:185-194.

19 Raza H, John A: Glutathione metabolism and oxidative stress in neonatal rat tissues from streptozotocininduced diabetic mothers. Diabetes Metab Res Rev 2004;20:72-78.

20 Raza H, John A, Howarth FC: Alterations in glutathione redox metabolism, oxidative stress, and mitochondrial function in the left ventricle of elderly Zucker diabetic Fatty rat heart. Int J Mol Sci 2012;13:16241-16254.

-21 Bhagwat SV, Mullick J, Raza H, Avadhani NG: Constitutive and inducible cytochromes P450 in rat lung mitochondria: xenobiotic induction, relative abundance, and catalytic properties. Toxicol Appl Pharmacol 1999;156:231-240.

-22 Raza H, Ahmed I, Lakhani MS, Sharma AK, Pallot D, Montague W: Effect of bitter melon (Momordica charantia) fruit juice on the hepatic cytochrome P450-dependent monooxygenases and glutathione S-transferases in streptozotocin-induced diabetic rats. Biochem Pharmacol 1996;52:1639-1642.

23 Birch-Machin MA, Turnbull DM: Assaying mitochondrial respiratory complex activity in mitochondria isolated from human cells and tissues. Methods Cell Biol 2001;65:97-117.

24 Laemmli UK: Cleavage of structural proteins during the assembly of the head of bacteriophage T4. Nature 1970;227:680-685.

25 Towbin H, Staehelin T, Gordon J: Electrophoretic transfer of proteins from polyacrylamide gels to nitrocellulose sheets: procedure and some applications. Proc Natl Acad Sci USA 1979;76:4350-4354.

-26 Bernhard D, Wang XL: Smoking, oxidative stress and cardiovascular diseases--do anti-oxidative therapies fail? Curr Med Chem 2007;14:1703-1712.

-27 Talukder MA, Johnson WM, Varadharaj S, Lian J, Kearns PN, El-Mahdy MA, Liu X, Zweier JL: Chronic cigarette smoking causes hypertension, increased oxidative stress, impaired NO bioavailability, endothelial dysfunction, and cardiac remodeling in mice. Am J Physiol Heart Circ Physiol 2011;300:H388-396. 


\section{Cellular Physiology $\quad$ Cell Physiol Biochem 2013;31:683-692 and Biochemistry

28 Pryor WA: Cigarette smoke radicals and the role of free radicals in chemical carcinogenicity. Environ Health Perspect 1997;105:875-882.

29 Bilimoria MH, Ecobichon DJ: Protective antioxidant mechanisms in rat and guinea pig tissues challenged by acute exposure to cigarette smoke. Toxicology 1992;72:131-144.

-30 Duong C, Seow HJ, Bozinovski S, Crack PJ, Anderson GP, Vlahos R: Glutathione peroxidase-1 protects against cigarette smoke-induced lung inflammation in mice. Am J Physiol Lung Cell Mol Physiol 2010;299:L425-433.

-31 Wardlaw SA, Nikula KJ, Kracko DA, Finch GL, Thornton-Manning JR, Dahl AR: Effect of cigarette smoke on CYP1A1, CYP1A2 and CYP2B1/2 of nasal mucosae in F344 rats. Carcinogenesis 1998;19:655-662.

-32 Alonso JR, Cardellach F, Casademont J, Miró O: Reversible inhibition of mitochondrial complex IV activity in PBMC following acute smoking. Eur Respir J 2004;23:214-218.

33 Rico de Souza A, Zago M, Pollock SJ, Sime PJ, Phipps RP, Baglole CJ: Genetic ablation of the aryl hydrocarbon receptor causes cigarette smoke-induced mitochondrial dysfunction and apoptosis. J Biol Chem 2011;286:43214-43228.

-34 Gvozdjáková A, Bada V, Sány L, Kucharská J, Krutý F, Bozek P, Trstanský L, Gvozdják J: Smoke cardiomyopathy: disturbance of oxidative processes in myocardial mitochondria. Cardiovasc Res 1984;18:229-232.

-35 Ghilarducci DP, Tjeerdema RS: Fate and effects of acrolein. Rev Environ Contam Toxicol 1995;144:95-146.

-36 Raza H, John A: 4-hydroxynonenal induces mitochondrial oxidative stress, apoptosis and expression of glutathione S-transferase A4-4 and cytochrome P450 2E1 in PC12 cells. Toxicol Appl Pharmacol 2006;16:309-318.

-37 Kosmider B, Messier EM, Chu HW, Mason RJ: Human alveolar epithelial cell injury induced by cigarette smoke. PLoS One 2011;6:e26059.

-38 van der Toorn M, Rezayat D, Kauffman HF, Bakker SJ, Gans RO, Koëter GH, Choi AM, van Oosterhout AJ, Slebos DJ: Lipid-soluble components in cigarette smoke induce mitochondrial production of reactive oxygen species in lung epithelial cells. Am J Physiol Lung Cell Mol Physiol 2009;297:L109-114. 